\title{
Letter to the Editor: Disc Space Preparation in Transforaminal Lumbar Interbody Fusion: A Comparison of Minimally Invasive and Open Approaches
}

\author{
Changkun Zheng MD, Jian-Jun Wu MD
}

To the editor,

e read the article by Rihn
and colleagues [2] with
great interest.

In the study, the authors randomly assigned 40 lumbar levels (L1-2 to L5S1) from eight fresh cadaver specimens to open and minimally invasive

(RE: Rihn JA, Gandhi SD, Sheehan P, Vaccaro AR, Hilibrand AS, Albert TJ, Anderson DG. Disc Space Preparation in Transforaminal Lumbar Interbody Fusion: A Comparison of Minimally Invasive and Open Approaches. [Published online ahead of print February 13, 2014]. Clin Orthop Rel Res. DOI: 10.1007/s11999-014-3479-z).

The authors certify that they, or any members of their immediate families, have no funding or commercial associations (eg, consultancies, stock ownership, equity interest, patent/licensing arrangements, etc.) that might pose a conflict of interest in connection with the submitted article. All ICMJE Conflict of Interest Forms for authors and Clinical Orthopaedics and Related Research ${ }^{\circledR}$ editors and board members are on file with the publication and can be viewed on request.

The opinions expressed are those of the writers, and do not reflect the opinion or policy of $C O R R^{\circledR}$ or the Association of Bone and Joint Surgeons ${ }^{\circledR}$. surgery (MIS) groups using a random number generator. We do not know the discectomy levels assigned to MIS or the open approach. Additionally, the clinical significance of disc space preparation regarding fusion rate or clinical outcome was not addressed. We wondered how the authors believe readers might make use of this study's findings given that the discectomy levels studied might have had an influence, and given the fact that this laboratory study could not speak to clinical outcome or even fusion rate.

The authors do not suggest that Transforaminal Lumbar Interbody Fusion (TLIF) is superior to other surgical approaches. However, data exists that calls into question the clinical benefit of the TLIF procedure compared with other methods of lumbar fusion [1, 3]. Regarding the adequacy of disc space preparation, the authors

C. Zheng MD (凶), J.-J. Wu MD Department of Orthopaedics, The Fuzhou Second Hospital, Xiamen University, Fuzhou 350007, Fujian, China

e-mail: zck2003@163.com concluded that when performed by a surgeon experienced with MIS TLIF, MIS and open approaches are similar. In light of this controversy, should we be focused on whether and when to perform TLIF, rather than how?

\section{References}

1. Goldstein CL, Macwan K, Sundararajan K, Rampersaud YR. Comparative outcomes of minimally invasive surgery for posterior lumbar fusion: a systematic review. Clin Orthop Relat Res. 2014;472:1727-1737.

2. Rihn JA, Gandhi SD, Sheehan P, Vaccaro AR, Hilibrand AS, Albert TJ, Anderson DG. Disc Space Preparation in Transforaminal Lumbar Interbody Fusion: A Comparison of Minimally Invasive and Open Approaches. [Published online ahead of print February 13, 2014]. Clin Orthop Rel Res. DOI: 10.1007/ s11999-014-3479-z.

3. Seng C, Siddiqui MA, Wong KP, Zhang K, Yeo W, Tan SB, Yue WM. Five-year outcomes of minimally invasive versus open transforaminal lumbar interbody fusion: a matchedpair comparison study. Spine (Phila $P a$ ). 2013;38:2049-2055. 